\title{
Monitoring the understory in eucalyptus plantations using airborne laser scanning
}

\author{
Alessandra Morais Melo ${ }^{1}$, Cristiano Rodrigues Reis ${ }^{*}{ }^{(0)}$, Bruno Ferraz Martins $^{3}{ }^{(0}$, Tamires Mousslech Andrade Penido ${ }^{10}$, Luiz Carlos \\ Estraviz Rodriguez ${ }^{2}$, Eric Bastos Gorgens ${ }^{10}$
}

\author{
'Universidade Federal dos Vales do Jequitinhonha e Mucuri/ \\ FCA - Depto. de Engenharia Florestal, Rod. MGT 367, km \\ 583, 5000 - 39100-000 - Diamantina, MG - Brasil. \\ 2Universidade de São Paulo/ESALQ - Depto. de Ciências \\ Florestais, Av. Pádua Dias, 11 - 13418-900 - Piracicaba, \\ $\mathrm{SP}$ - Brasil. \\ ${ }^{3}$ Celulose Nipo-Brasileira S.A., Rod. BR 381, km 172 - \\ 35196-000 - Belo Oriente, MG - Brasil. \\ *Corresponding author <cristiano.reis@usp.br>
}

Edited by: Rafael Rubilar Pons / Paulo Cesar Sentelhas

Received May 14, 2019

Accepted August 08, 2019
ABSTRACT: In eucalyptus plantations, the presence of understory increases the risk of fires, acts as an obstacle to forest operations, and leads to yield losses due to competition. The objective of this study was to develop an approach to discriminate the presence or absence of understory in eucalyptus plantations based on airborne laser scanning surveys. The bimodal canopy height profile was modeled by two Weibull density functions: one to model the canopy, and other to model the understory. The parameters used as predictor in the logistic model successfully discriminated the presence or absence of understory. The logistic model composed by $\gamma_{\text {canopyy }} \gamma_{\text {understory }}$ and $\gamma_{\text {understory }}$ showed higher values of accuracy (0.96) and kappa (0.92), which means an adequate classification of presence of understory and absence of understory. Weibull parameters could be used as input in the logistic regression to effectively identify the presence and absence of understory in eucalyptus plantation.

Keywords: LiDAR, remote sensing, weed control, understory vegetation

\section{Introduction}

Forest plantations provide edaphic and microclimatic conditions that benefit the development of weeds in the understory (Vasic et al., 2012). Competition for site resources (water, light, and nutrients) resulting from the presence of understory in early stages of the forest, causes forest productivity loss (Carrero et al., 2018; Rubilar et al., 2018). In late stages, the understory presence results in problems for silviculture treatments, monitoring activities (i.e. inventory), harvesting operations, and risks of fires (Souza et al., 2007).

Understory control is usually applied during the early stages of the forest to improve the establishment of trees, ensuring full access to growth factors (Kogan et al., 2002; Liechty and Fristoe, 2013; Vargas et al., 2018; Zhou et al., 2018). The most common practices to control understory development in forest plantations are hoeing and herbicides application (Silva et al., 2012; Toledo et al., 2000).

Assessment of understory intensity in forest plantations is commonly based on visual and empirical monitoring. Recent studies have investigated the capability of remote sensing (RS) for monitoring (Hamraz et al., 2017a, b; Martinuzzi et al., 2009; Sumnall et al., 2016) and classification of understory (Hung et al., 2014). Several approaches have been used to estimate forest physical characteristics (i.e. volume, biomass, stand density) from LiDAR point cloud, such as the regression model (Sumnall et al., 2016), probability density function modeling (Coops et al., 2007), and machine learning (Singh et al., 2015). Discrete-return light detection and ranging (LiDAR) is capable to characterize vertical forest structure, including understory layers (Hamraz et al., 2017a, b; Sumnall et al., 2016). The canopy height profile (CHP) describes the vertical structure by the return frequency distribution within the canopy profile, from the ground to the maximum height. This study aims to develop a machine learning based on logistic regression to classify the occurrence or absence of understory based on the CHP extracted from airborne laser scanning data.

\section{Materials and Methods}

Four forest plantation sites in the Rio Doce basin, Minas Gerais State, Brazil (Figure 1) were considered in this study. The sites belong to a private company that produces cellulose from eucalyptus fiber, and comprise legal reserves, areas of permanent protection, and eucalyptus plantation. Legal reserves and areas of permanent protection are regions of native vegetation protected by law (Machado and Anderson, 2016). This study focuses on plantation areas.

The municipalities of Marliéria, Dionísio, and Açucena have a tropical climate with dry winters (Köppen - Aw). The municipality of Antônio Dias has a humid subtropical climate with dry winters and temperate summers (Cwb). The climate of Nova Era and Bela Vista of Minas is characterized by hot summers and dry winters (Cwa). All sites have annual rainfall ranging from $1361 \mathrm{~mm}$ to $1520 \mathrm{~mm}$ and mean annual temperatures ranging from $19.8{ }^{\circ} \mathrm{C}$ to $21.8{ }^{\circ} \mathrm{C}$ (Alvares et al., 2013).

Area I comprised 96 ha of 23-year-old eucalyptus stands. Area II consisted of 21-year-old eucalyptus stands, covering $47 \mathrm{ha}$. Area III was composed by 17 -year-old eucalyptus stands planted in 222 ha. Finally, Area IV comprised 242 ha of 5-year-old eucalyptus stands. The highest values for tree height and diameter at breast height (DBH) were found in the older stands (areas I and II). The younger stands are in Area IV, resulting in lower heights and DBH values (Table 1). 

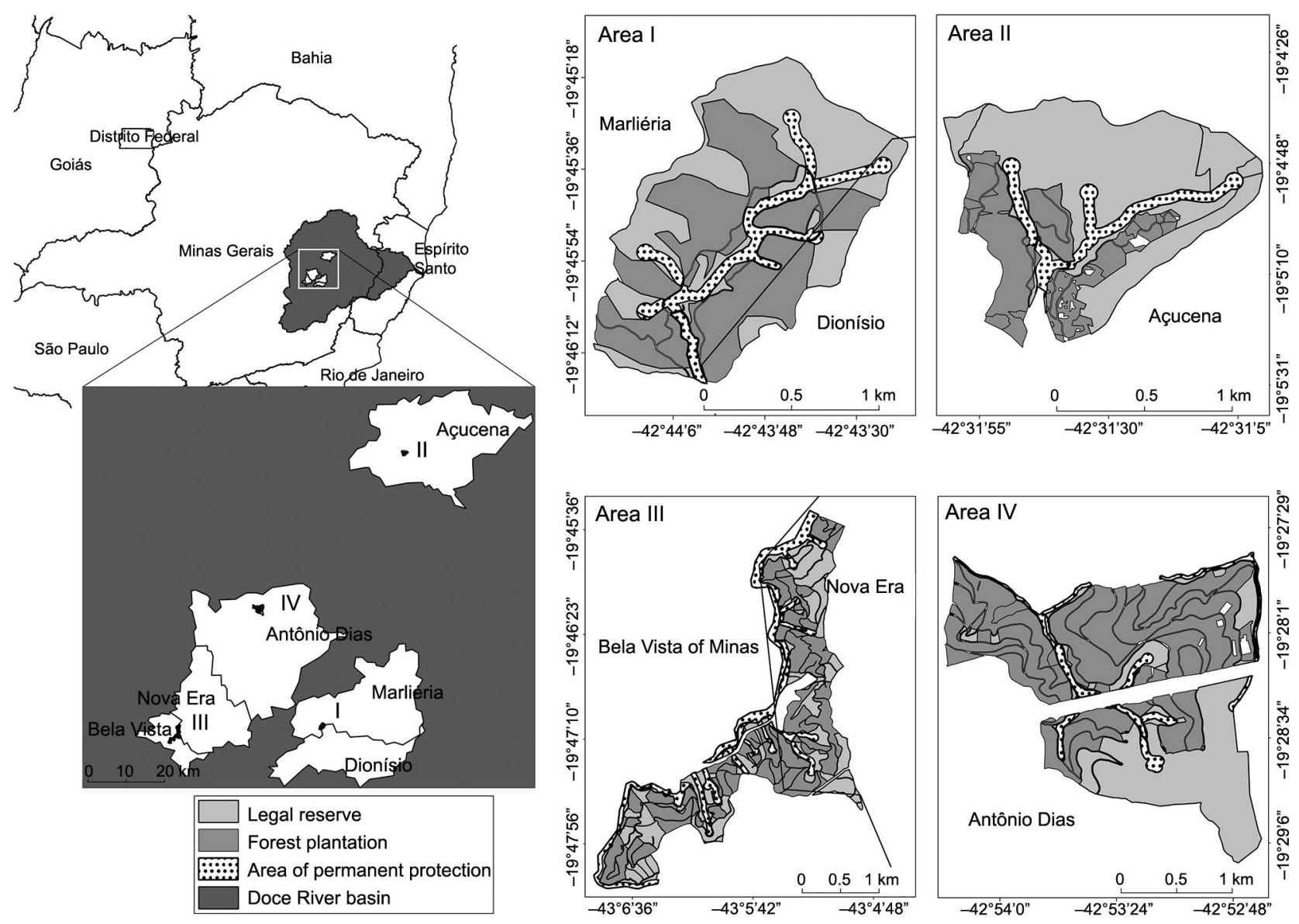

Figure 1 - Municipalities where the four sites are located. Panels show land use for each study area.

Table 1 - Descriptive summary of the eucalyptus plantation sites, located in the Doce River Basin, Minas Gerais State. DBH = diameter at breast height.

\begin{tabular}{lcccc}
\hline & Area I & Area II & Area III & Area IV \\
\hline Elevation (m above sea level) & $531-803$ & $534-723$ & $530-784$ & $911-1212$ \\
Maximum tree height $(\mathrm{m})$ & 47.82 & 47.65 & 37.24 & 23.94 \\
Minimum tree height $(\mathrm{m})$ & 26.53 & 24.84 & 20.97 & 18.12 \\
Average tree height $(\mathrm{m})$ & 37.44 & 34.95 & 29.56 & 22.55 \\
Maximum DBH $(\mathrm{cm})$ & 45.77 & 37.90 & 34.44 & 18.66 \\
Minimum DBH $(\mathrm{cm})$ & 13.75 & 11.10 & 11.32 & 10.23 \\
Average DBH $(\mathrm{cm})$ & 26.81 & 22.89 & 21.42 & 15.94 \\
Number of trees per hectare & 535 & 942 & 825 & 1037 \\
\hline
\end{tabular}

In the GIS environment, we sampled randomly 50 circular plots of $16.93 \mathrm{~m}$ radius $\left(900 \mathrm{~m}^{2}\right)$ in each site, resulting in 200 plots. None of the plots overlapped. The sites were visited and the presence or absence of understory was visually determined by walking through the stands, following the company standards. During regular company operations (e.g. ant control, fertilization, or forest inventory), workers visually identify understory presence and report it to the responsible sector. The company assigns a specialized group to the area in order to assess understory intensity and species community. Due to limitations of LiDAR technology further discussed, this study did not aim to evaluate the species community of the understory.

The airborne laser scanning (ALS) campaign was conducted in 2014, in the same period of field inspection. The ALS clouds presented an average return density of 13.51 pts $\mathrm{m}^{-2}, 9.26$ pts $\mathrm{m}^{-2}, 9.23$ pts $\mathrm{m}^{-2}, 7.87 \mathrm{pts}^{-2}$, for Areas I, II, III, IV, respectively.

We applied an outlier filter in the original ALS clouds to remove the returns outside the range of four standard-deviation (McGaughey, 2015). The ground returns were classified by Kraus and Pfeifer (1998; 2001) algorithm considering an 8-meter window size (Andrade et al., 2018) and parameters recommended by McGaughey (2015). Digital terrain models (DTM) with 1-meter resolution was created by averaging the ground points within each pixel. The ALS clouds were normalized by subtracting each return elevation by the corresponding DTM pixel (Popescu and Wynne, 2004).

From the normalized clouds, we clipped the same 200 plots inspected in the field and computed the return distribution along with the canopy height (CHP). To 
reduce the influence of the growth stage (young stands with smaller trees and old stands with taller trees) in the logistic modeling, we rescaled the CHP to the range between zero (ground) and one (maximum height). By processing the data, we visually detected that the normalized CHP showed a common division in the half of the normalized height, producing consistently bimodal profiles (Figure 2). Due to this behavior, we established the value 0.5 as a breaking point to split the CHP into two parts: canopy and understory. One Weibull model fitted the canopy (returns above 0.5) and other the understory (return below 0.5) (Figure 2).

The Weibull function of two parameters (Equation 1) is commonly used to model the CHP due to its flexibility in the representation of different distribution shapes (Coops et al., 2007; Silva et al., 2015).

$$
f(x, \beta, \gamma)=\left\{\begin{array}{c}
\frac{\gamma}{\beta}\left(\frac{x}{\beta}\right)^{\gamma-1} e\left[-\left(\frac{x}{\beta}\right)^{\gamma}\right], \forall x \geq 0 \\
0, \forall x<0
\end{array}\right.
$$

where: the Weibull probability density function is a function of the lidar-plots heights $(x)$, shape $(\gamma)$ and scale ( $\beta)$ parameters.

The Weibull coefficients $\left(\gamma_{\text {canopy' }} \beta_{\text {canopy }} \gamma_{\text {understory' }}\right.$ and $\beta_{\text {understory }}$ / was used as predictor variables in the logistic modeling, and the understory classified in the field (presence or absence) as the predicted variable (Equation $2)$. To validate the model, we used the stratified ten-fold cross-validation method (Singh et al., 2015).

$$
\begin{gathered}
\log _{e}\left[\frac{P}{1-P}\right]=\operatorname{logit}(P)=\alpha_{0}+\alpha_{1} \beta_{\text {understory }}+\alpha_{2} \gamma_{\text {understory }}+ \\
\alpha_{3} \beta_{\text {canopy }}+\alpha_{4} \gamma_{\text {canopy }}
\end{gathered}
$$

where: $\operatorname{logit}(P)$ is the odds ratio, $P$ is the probability of understory occurrence, $\gamma_{\text {canopy' }} \beta_{\text {canopy' }} \gamma_{\text {understory' }}$ and $\beta_{\text {understory }}$ obtained from the Weibull distribution modeling are the predictor variables, and $\alpha$ 's are the logistic regression parameters.
Logistic regression is a machine-learning algorithm that estimates the probability of an event occurring (Dangeti, 2017). The logistic regression is based on classical statistics assumptions (Singh et al., 2015) and returns a statistical report that makes interpretation easier (Cutler et al., 2007). The logistic regression parameters were statistically analyzed using a z-test to confirm their ability to classify the occurrence of the understory in the eucalyptus stands. The non-significant predictors were removed and the logistic regression parameters were estimated again. The significance of the logistic regression parameters indicates the capacity of predictors to distinguish the presence or absence of understory (Smart et al., 2012). The modeling was evaluated through Akaike Information Criterion (AIC), analysis of variance, accuracy, and the kappa agreement index.

We used FUSION (version 3.60; McGaughey, 2015 ) and $R$ (version 3.4.3) to process the data. The code is available at https://github.com/Gorgens/precisionFor/ tree/master/chp.

\section{Results}

The CHM from plots with dense understory showed a bell-shaped curve for both canopy and understory. For plots with no understory, the canopy revealed a bell-shaped curve, whereas the understory showed a negative exponential curve (Figure 3).

The logistic coefficient associated with the $\beta_{\text {canopy }}$ variable in model 1 (Table 2) was not significant $(p>$ 0.05). After removing the non-significant variable, the logistic model 2 (Table 2) was significant $(p<0.01)$ to discriminate the presence or absence of understory. Each variable was significantly important $(p<0.001)$ to reduce deviance compared to the model with only the intercept. Additionally, the lower AIC of model 2 (79.22) reinforces its better fit in comparison to model 1 (80.06).

The coefficients of model 2 showed that the probability of understory occurrence decreased as

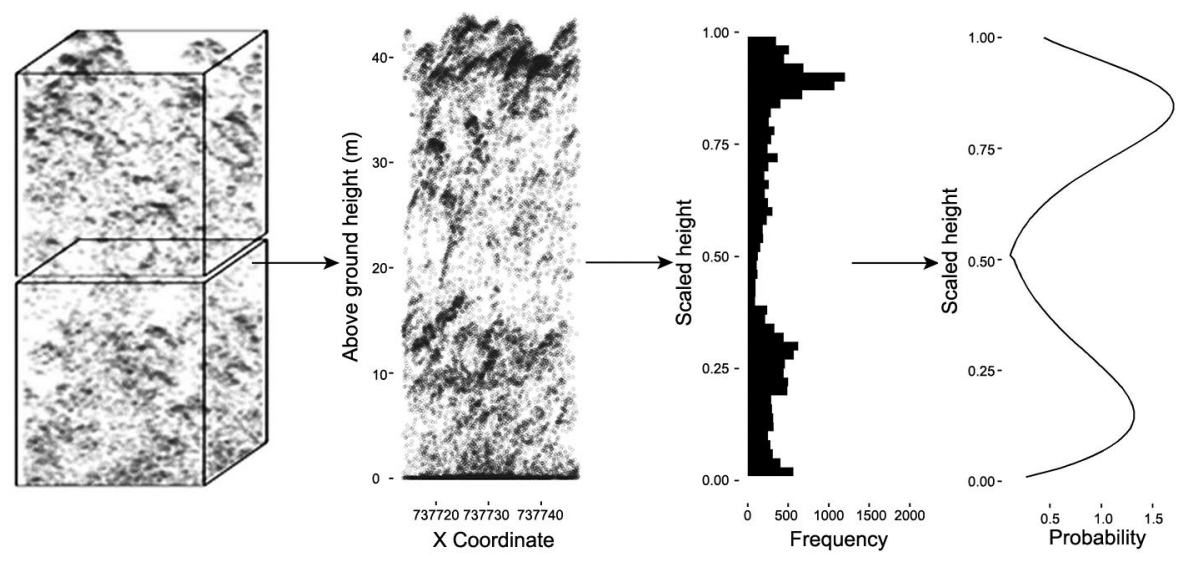

Figure 2 - Processing steps to model the canopy height profile. From left to right: three-dimensional plot; two-dimension plot; canopy height profile; two Weibull probability density functions fitted: one for the canopy and another for the understory. 

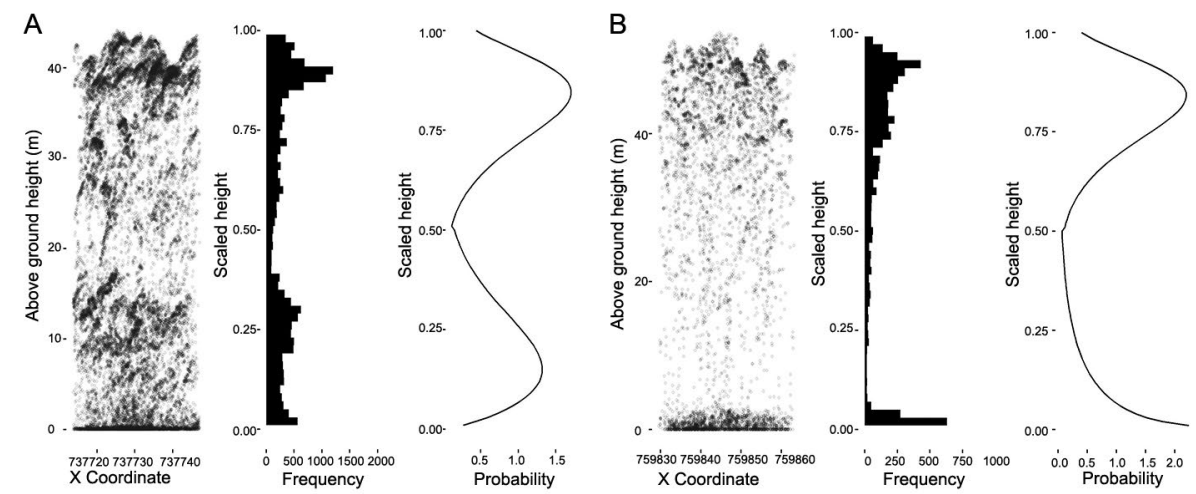

Figure 3 - Two examples of vertical profiles. a) plot with dense understory and b) plot with no understory. Each panel presents 2D representation, canopy height profile, and Weibull probability density function for canopy and understory.

Table 2 - Logistic model with the estimated coefficients, where logit $(P)$ means the odds ratio, $P$ is the probability of understory occurrence, $\gamma_{\text {canopy' }} \beta_{\text {canopy }}, \gamma_{\text {understory }}$ and $\beta_{\text {understory }}$ are the explanatory variables obtained from the Weibull distribution modeling, AIC is the Akaike information criterion, $\mathrm{A}$ is the model accuracy, and $\mathrm{K}$ is the kappa index.

\begin{tabular}{|c|c|c|c|c|}
\hline Model & Logistic regression coefficients & AIC & A & K \\
\hline 1 & $\begin{aligned} \operatorname{logit}(P) & =7.54-21.74 \beta_{\text {understory }} \\
& +14.52 \gamma_{\text {understory }}-12.87 \beta_{\text {canopy }} \\
& -1.12 \gamma_{\text {canopy }}\end{aligned}$ & 80.06 & 0.945 & 0.90 \\
\hline 2 & $\begin{aligned} \operatorname{logit}(P) & =-1.51-22.39 \beta_{\text {understory }} \\
& +14.44 \gamma_{\text {understory }}-1.27 \gamma_{\text {canopy }}\end{aligned}$ & 79.22 & 0.96 & 0.92 \\
\hline
\end{tabular}

$\beta_{\text {understory }}$ and $\gamma_{\text {canopy }}$ increased. Differently, increasing $\gamma_{\text {understory }}$ contributed to increase the probability of understory presence (Table 2).

Model 2 showed higher values of accuracy (0.96) and kappa (0.92), which means an improvement in the discrimination power (Table 2). Model 2 can be used to adequately classify as presence (specificity $=0.95$ ) and absence (sensitivity $=0.95$ ) of understory. The confusion matrix showed 95 plots correctly classified with understory presence, and 97 were correctly classified with understory absence. Five plots resulted in false positives and three in true positives, based on model 2.

\section{Discussion}

The return density of lidar point clouds (ranging from 7.8 to $13.5 \mathrm{pts}^{-2}$ ) captured the bimodal distribution that usually characterizes a forest CHP (Mund et al., 2015). The CHP differentiated the presence and absence of understory mainly by the shape of the lower part of CHP (scaled height $<0.5$ in Figure 2).

A multi-layered forest blocks the laser energy pathway to the ground. In eucalyptus plantations with no understory, a multimodal distribution can be observed (Coops et al., 2007; Görgens et al., 2016). One mode is associated to the canopy (a bell-shaped curve) and another to the ground (negative exponential curve) (Görgens et al., 2016). When understory is present in forest plantations, the lower mode generally moves up, changing the shape of the distribution curve into a bellshaped curve (Figure 2).

Despite the importance of understory in the ecosystem ecology and biomass storage (Hamraz et al., 2017b), the CHP is an important descriptor to predict fire behavior (Andersen et al., 2005), determine leaf area index (Lefsky et al., 1999; Jensen et al., 2008), characterize forest types (Lovell et al., 2003; Maltamo et al., 2004; Coops et al., 2007; Dean et al., 2009), and monitor forest plantations competition.

The Weibull parameters successfully identified the presence or absence of understory, showing $96 \%$ of accuracy. Weibull models have been an important descriptor for the forest structure, reducing the CHP into values that could be quickly interpreted (Coops et al., 2007; Jaskierniak et al., 2011).

The $\beta$ coefficient is related to the $63^{\text {rd }}$ distribution percentile (Bailey and Dell, 1973). The $\beta_{\text {understory }}$ coefficients presented higher values in presence of understory, which means that laser beams were intercepted by obstacles above ground. The $\gamma_{\text {understory }}$ coefficients revealed lower values (close to one) in the absence of understory, indicating that the distribution curve approaches an exponential format (Bailey and Dell, 1973).

Wing et al. (2012) found an accuracy of $22 \%$ using ALS-derived metric and a logistic regression model to predict understory in pine forest. In another study, random forest algorithm based on ALS-derived metrics predicted the presence or absence of understory, reaching an accuracy of $83 \%$ in a coniferous forest (Martinuzzi et al., 2009). Singh et al. (2015) found a kappa of 0.648 using a random forest to detect plant invasion in the understory of urban forests. Our accuracy and kappa were superior to previous studies. We attribute part of the improvement to modeling the CHP into two parts: canopy and understory, and to the use of Weibull parameters as regressors. 
Currently, it is common in classification studies to apply modern machine learning as random forest and support vector machine. However, as suggested by Singh et al. (2015), the logistic regression is based on classical statistical assumptions and has very direct interpretation. The high values obtained for the accuracy and kappa index reinforce suitability of the logistic regression. The kappa index confirmed a good agreement between the logistic regression classification and the field truth (Silván-Cárdenas and Wang, 2006).

Identification of the understory species is important to define the proper control approach (Silva et al., 2012). However, monochromatic remote sensing, such as airborne laser scanning, is not ideal for species differentiation. Hyperspectral images have been studied to fill this gap when surveyed together with ALS (Broadbent et al., 2014; Dalponte et al., 2019).

Correct mapping of the understory is essential to avoid competition for growth factors by planning silviculture actions. The logistic regression using the Weibull parameters as input performed well and the final model seems appropriated to discriminate presence or absence of understory in eucalyptus plantation. We recommend further investigation to explore the influence of different silvicultural regimes (e.g. higher density of trees) and discriminate species using complementary remote sensing techniques (e.g. hyperspectral).

\section{Acknowledgement}

We thank Celulose Nipo-Brasileira S.A. (CENIBRA) for supply the ALS data and field information for this work. We also thank Universidade Federal dos Vales do Jequitinhonha e Mucuri (UFVJM), Conselho Nacional de Desenvolvimento Científico e Tecnológico (CNPq), Coordenação de Aperfeiçoamento de Pessoal de Nível Superior (CAPES) and Fundação de Amparo à Pesquisa do Estado de Minas Gerais (FAPEMIG).

\section{Authors' Contributions}

Conceptualization: Melo, A.M.; Gorgens, E.B. Design of Methodology: Melo, A.M.; Gorgens, E.B. Data acquisition: Melo, A.M.; Martins, B.F. Data analysis: Melo, A.M.; Gorgens, E.B.; Reis, C.R. Software development: Melo, A.M.; Gorgens, E.B.; Reis, C.R. Writing and editing: Melo, A.M.; Gorgens, E.B.; Reis, C.R.; Martins, B.F.; Penido, T.M.A.; Rodriguez, L.C.E.

\section{References}

Alvares, C.A.; Stape, J.L.; Sentelhas, P.C.; Gonçalves, J.L.M.; Sparovek, G. 2013. Köppen's climate classification map for Brazil. Meteorologische Zeitschrift 22: 711-728.

Andersen, H.-E.; McGaughey, R.J.; Reutebuch, S.E. 2005. Estimating forest canopy fuel parameters using LIDAR data. Remote Sensing of Environment 94: 441-449.
Andrade, M.S.; Görgens, E.B.; Reis, C.R.; Cantinho, R.Z.; Assis, M.; Sato, L.; Ometto, J.P.H.B. 2018. Airborne laser scanning for terrain modeling in the Amazon forest. Acta Amazônica 48: 271-279.

Bailey, R.L.; Dell, T.R. 1973. Quantifying diameter distributions with the Weibull function. Forest Science 19: 97-104.

Broadbent, E.N.; Zambrano, A.M.A.; Asner, G.P.; Field, C.B.; Rosenheim, B.E.; Kennedy-Bowdoin, T.; Knapp, D.E.; Burke, D.; Giardina, C.P.; Cordell, S. 2014. Linking rainforest ecophysiology and microclimate through fusion of airborne LiDAR and hyperspectral imagery. Ecosphere 5: article 57.

Carrero, O.; Stape, J.L.; Allen, L.; Arrevillaga, M.C.; Ladeira, M. 2018. Productivity gains from weed control and fertilization of short-rotation Eucalyptus plantations in the Venezuelan western Llanos. Forest Ecology and Management 430: 566-575.

Coops, N.C.; Hilker, T.; Wulder, M.A.; St-Onge, B.; Newnham, G.; Siggins, A.; Trofymow, J.A. 2007. Estimating canopy structure of Douglas-fir forest stands from discrete-return LiDAR. Trees 21: 295-310.

Cutler, D.R.; Edwards, T.C.; Beard, K.H.; Cutler, A.; Hess, K.T.; Gibson, J.; Lawler, J.J. 2007. Random forests for classification in ecology. Ecology 88: 2783-2792.

Dalponte, M.; Frizzera, L.; Gianelle, D. 2019. Individual tree crown delineation and tree species classification with hyperspectral and LiDAR data. PeerJ 6: e6227.

Dangeti, P. 2017. Statistics for machine learning: techniques for exploring supervised, unsupervised, and reinforcement learning models with Python and R. Packt, Birmingham, UK.

Dean, T.J.; Cao, Q. V.; Roberts, S.D.; Evans, D.L. 2009. Measuring heights to crown base and crown median with LiDAR in a mature, even-aged loblolly pine stand. Forest Ecology and Management 257: 126-133.

Characterization of brazilian forest types utilizing canopy height profiles derived from airborne laser scanning. Applied Vegetation Science 19: 518-527.

Hamraz, H.; Contreras, M.A.; Zhang, J. 2017a. Vertical stratification of forest canopy for segmentation of understory trees within small-footprint airborne LiDAR point clouds. ISPRS Journal of Photogrammetry and Remote Sensing 130: 385-392.

Hamraz, H.; Contreras, M.A.; Zhang, J. 2017b. Forest understory trees can be segmented accurately within sufficiently dense airborne laser scanning point clouds. Scientific Reports 7: 6770.

Hung, C.; Xu, Z.; Sukkarieh, S. 2014. Feature learning based approach for weed classification using high resolution aerial images from a digital camera mounted on a UAV. Remote Sensing 6: 12037-12054.

Jaskierniak, D.; Lane, P.N.J.; Robinson, A.; Lucieer, A. 2011. Extracting LiDAR indices to characterise multilayered forest structure using mixture distribution functions. Remote Sensing of Environment 115: 573-585.

Jensen, J.L.R.; Humes, K.S.; Vierling, L.A.; Hudak, A.T. 2008. Discrete return lidar-based prediction of leaf area index in two conifer forests. Remote Sensing of Environment 112: 39473957.

Kogan, M.; Figueroa, R.; Gilabert, H. 2002. Weed control intensity effects on young radiata pine growth. Crop Protection 21: 253-257. 
Kraus, K.; Pfeifer, N. 1998. Determination of terrain models in wooded areas with airborne laser scanner data. ISPRS Journal of Photogrammetry and Remote Sensing 53: 193-203.

Kraus, K.; Pfeifer, N. 2001. Advanced DTM generation from LIDAR data. International Archives of Photogrammetry Remote Sensing and Spatial Information Sciences 34: 23-30.

Lefsky, M.A.; Cohen, W.B.; Acker, S. A.; Parker, G.G.; Spies, T.A.; Harding, D. 1999. Lidar remote sensing of the canopy structure and biophysical properties of Douglas-Fir western Hemlock forests. Remote Sensing of Environment 70: 339-361.

Liechty, H.O.; Fristoe, C. 2013. Response of midrotation pine stands to fertilizer and herbicide application in the western Gulf Coastal Plain. Southern Journal of Applied Forestry 37: 69-74.

Lovell, J.L.; Jupp, D.L.B.; Culvenor, D.S.; Coops, N.C. 2003. Using airborne and ground-based ranging lidar to measure canopy structure in Australian forests. Canadian Journal of Remote Sensing 29: 607-622.

Machado, F.; Anderson, K. 2016. Brazil's New Forest Code: A Guide for Decision-Makers in Supply Chains and Governments. WWF, Brasília, DF, Brazil.

Maltamo, M.; Eerikäinen, K.; Pitkänen, J.; Hyyppä, J.; Vehmas, M. 2004. Estimation of timber volume and stem density based on scanning laser altimetry and expected tree size distribution functions. Remote Sensing of Environment 90: 319-330.

Martinuzzi, S.; Vierling, L.A.; Gould, W.A.; Falkowski, M.J.; Evans, J.S.; Hudak, A.T.; Vierling, K.T. 2009. Mapping snags and understory shrubs for a LiDAR-based assessment of wildlife habitat suitability. Remote Sensing of Environment 113: 2533-2546.

McGaughey, R.J. 2015. FUSION/LDV: Software for LiDAR Data Analysis and Visualization. US Department of Agriculture, Washington, DC, USA.

Mund, J.-P.; Wilke, R.; Körner, M.; Schultz, A. 2015. Detecting multi-layered forest stands using high density airborne LiDAR data. Journal of Geographical Information Science 1: 178-188.

Popescu, S.C.; Wynne, R.H. 2004. Seeing the trees in the forest: using LiDAR and multispectral data fusion with local filtering and variable window size for estimating tree height. Photogrammetric Engineering \& Remote Sensing 70: 589-604.

Rubilar, R.A.; Lee Allen, H.; Fox, T.R.; Cook, R.L.; Albaugh, T.J.; Campoe, O.C. 2018. Advances in silviculture of intensively managed plantations. Current Forestry Reports 4: 23-34.

Silva, A.G.P.; Görgens, E.B.; Campoe, O.C.; Alvares, C.A.; Stape, J.L.; Rodriguez, L.C.E. 2015. Assessing biomass based on canopy height profiles using airborne laser scanning data in eucalypt plantations. Scientia Agricola 72: 504-512.
Silva, J.R.V.; Alves, P.L.D.C.A.; Toledo, R.E.B. 2012. Weed control strip influences the initial growth of Eucalyptus grandis. Acta Scientiarum. Agronomy 34: 29-35.

Silván-Cárdenas, J.L.; Wang, L. 2006. A multi-resolution approach for filtering LiDAR altimetry data. ISPRS Journal of Photogrammetry and Remote Sensing 61: 11-22.

Singh, K.K.; Davis, A.J.; Meentemeyer, R.K. 2015. Detecting understory plant invasion in urban forests using LiDAR. International Journal of Applied Earth Observation and Geoinformation 38: 267-279.

Smart, L.S.; Swenson, J.J.; Christensen, N.L.; Sexton, J.O. 2012. Three-dimensional characterization of pine forest type and red-cockaded woodpecker habitat by small-footprint, discretereturn lidar. Forest, Ecology and Management 281: 100-110.

Souza, P.B.; Martins, S.V.; Costalonga, S.R.; Costa, G.O. 2007. Floristic and structure of tree-shrub vegetation in understory of Eucalyptus grandis W. Hill ex Maiden stands, in Viçosa, MG, Brazil. Revista Árvore 31: 533-543 (in Portuguese, with abstract in English).

Sumnall, M.J.; Hill, R.A.; Hinsley, S.A. 2016. Comparison of small-footprint discrete return and full waveform airborne lidar data for estimating multiple forest variables. Remote Sensing of Environment 173: 214-223.

Toledo, R.E.B.; Victória Filho, R.; Pitelli, R.A.; Alves, P.L.C.A.; Lopes, M.A.F. 2000. Effects of weed control periods on initial growth and development of Eucalypt. Planta Daninha 18: 395404 (in Portuguese, with abstract in English).

Vargas, F.; Rubilar, R.; Gonzalez-Benecke, C.A.; SanchezOlate, M.; Aracena, P. 2018. Long-term response to area of competition control in Eucalyptus globulus plantations. New Forests 49: 383-398.

Vasic, V.; Konstantinovic, B.; Orlovic, S. 2012. Weeds in forestry and possibilities of their control. p. 147-170. In: Price, A., ed. Weed control. InTech, Rijeka, Croatia.

Wing, B.M.; Ritchie, M.W.; Boston, K.; Cohen, W.B.; Gitelman, A.; Olsen, M.J. 2012. Prediction of understory vegetation cover with airborne lidar in an interior ponderosa pine forest. Remote Sensing of Environment 124: 730-741.

Zhou, X.; Zhu, H.; Wen, Y.; Goodale, U.M.; Li, X.; You, Y.; Ye, D.; Liang, H. 2018. Effects of understory management on trade-offs and synergies between biomass carbon stock, plant diversity and timber production in eucalyptus plantations. Forest Ecology and Management 410: 164-173. 